\title{
Trends in Triplet Stillbirth Rates in Japan, 1975-1998
}

\author{
Yoko Imaizumi' and Koichi Nonaka ${ }^{2}$ \\ ' Department of Health System Management, Faculty of Health Science, Hyogo University, Kakogawa City, Hyogo Prefecture, Japan \\ ${ }^{2}$ Department of Human Development, Faculty of Human Sciences, Wako University, Tokyo, Japan
}

$S^{t i}$ tillbirth rates of triplet births in the whole of Japan were analyzed using vital statistics from 1975 to 1998. Stillbirths were registered at 12 weeks gestation or later. The stillbirth rate was significantly higher in like- than in unlike-sex triplets for 1975-1998. During the 23-year period the stillbirth rate decreased from 342 to 49 per 1000 total births for like-sex and from 195 to 54 for unlike-sex triplets. The decrease in the stillbirth rate in the 23year period was greater in both like- and unlike-sex triplets than in singleton and twin births. Risk factors for stillbirth in triplets were like-sex, youngest or oldest maternal age groups, shorter gestational age and lower birthweight. It is recommended that the optimum period to give birth for triplet pregnancies is 34-35 weeks of gestation for Japanese women.

Elevated triplet birth rates since 1974 have been attributed to the higher proportion of mothers treated with ovulation-inducing hormones and in-vitro fertilization (IVF) (Derom et al., 1995; Jonas \& Lumley, 1993; Imaizumi,1998). Stillbirth rates are higher in monozygotic twins than in singletons and dizygotic twins (Barr \& Stevenson, 1961; Imaizumi \& Nonaka, 1998; West et al., 1999). The stillbirth rate was significantly higher in like- than unlike-sex triplets in Japan from 1955 to 1967 and in 1974 (Imaizumi \& Inouye, 1980). The stillbirth rate of triplets decreased from 640 per 1000 total births in 1961 to 380 in 1974.

The present study describes annual changes in stillbirth rates of triplets in Japan since 1974, as well as the effects of maternal age, sex composition of triplets, gestational age and birthweight on stillbirth rates of triplets.

\section{Materials and Methods}

Computerized vital statistics data on triplet births in Japan have been available since 1968. In this study, data for the period between 1975 and 1998 were analyzed. The stillbirth rate was calculated as the number of stillbirths per 1000 total births (live births plus stillbirths). Birth and "fetal death" certificate records included information on parental age, place of residence, sex of triplet births, date of live birth or stillbirth, gestational age and occupation of the head of household. In Japan, a "fetal death" is registered as a stillbirth if the delivery occurs at 12 or more completed weeks of gestation. The gestational age at delivery is not necessarily the fetal age at death.

Registration of births (live births and stillbirths) is made on an individual basis, giving three separate records for each triplet maternity. To identify each set of triplets we used information on the date of birth, place of residence (codes for prefecture, health center, and city or town within the prefecture), and ages of both parents. There were 14,328 triplet births (11,942 live births and 2386 stillbirths) during that period. Firstly, we sorted the records using the above key fields, and then checked adjacent records for their identity. If three adjacent records were identical for every field, they were judged as the co-triplets from a set. With this criterion we identified 4560 sets (13,680 births, or $95.5 \%$ of the total triplet births) with 648 births unmatched. To obtain more sets allowing for possible differences in birth dates and parental age, we repeated the above matching procedure for the remaining unmatched cases. At the second cycle, we allowed a maximum difference of 20 days between birth dates of co-triplets and 1 year difference in paternal and maternal ages for the adjacent three birth records. We further identified 120 sets, giving a total of 4680 sets of triplets $(98.0 \%$ of all the triplet births). In the 4680 sets there were 201 sets with one or more sex-unknown co-triplet(s). Thus 4479 sets were used to estimate the stillbirth rates for like- and unlike-sex triplets in the present analysis.

In Japan, the gestational age before 1979 was recorded in months, and after 1979, in weeks. Analyses according to gestational age were carried out with data on triplets born in the period from 1979 to 1998.

Received 15 September, 2003; accepted 18 March, 2004.

Address for correspondence: Yoko Imaizumi, Department of Health System Management, Faculty of Health Science, Hyogo University, Kakogawa City, Hyogo Prefecture, Japan. Email: imaizumi@humanskc.hyogo-dai.ac.jp 


\section{Results}

\section{Trends in Stillbirth Rates}

Table 1 shows like- and unlike-sex triplet deliveries according to survival states of triplets and the stillbirth rate of triplets from 1975 to 1998 . The stillbirth rate of like-sex triplets decreased from 342 per 1000 births in 1975 to 49 in 1998 . The stillbirth rate thus decreased to be one-seventh of what it was in 1979 . Similarly, the stillbirth rate of unlike-sex triplets gradually decreased from 195 in 1975 to 54 in 1998, a relative decrease of one-quarter. The linear regression of the stillbirth rate on the year gave coefficients $( \pm$ standard error) of $-0.010( \pm 0.001)$ for like-sex triplets and $-0.006( \pm 0.001)$ for unlike-sex triplets during the entire period: the coefficients were significantly different from zero at the $1 \%$ level for both types of triplets. The stillbirth rate was significantly higher in like- than in unlike-sex triplets for the period 1975-1998.

Table 1 also shows overall stillbirth rates of triplets and singletons. The overall stillbirth rate of triplets was 308 per 1000 births in 1975 and 75 in
1998, whereas the corresponding rates of sex-known triplet sets were 292 (106/363) and 52 (51/987), respectively. Thus, stillbirth rates of sex-known triplet sets were underestimated. The risk of stillbirth was 6fold higher in triplets than in singletons in 1975, and the relative risk decreased to 2.4-fold in 1998 .

There has been an almost complete reversal of the ratio. In 1975, there were 80 like- and 41 unlike-sex triplet deliveries, a ratio of almost 2:1 (see Table 1). In 1998, however, there were 116 like- and 211 unlikesex triplet deliveries, a ratio of almost 1:2.

\section{Stillbirth Rates According to Sex Composition and Maternal Age}

Table 2 shows stillbirth rates of like- and unlike-sex triplets according to maternal age during the period 1975-1998. The stillbirth rate of like-sex triplets decreased significantly along the six 4-year periods in each maternal age group except the age group less than 25 years. However, the only significant decrease for unlike-sex triplets was in the maternal age group between 25 and 29 years. With two exceptions, the stillbirth rate was higher in the like- than in the unlike-sex triplets in each maternal age group.

Table 1

Like- and Unlike-sex Triplet Deliveries According to Survival States of Triplets and Stillbirth Rates Among Triplet Deliveries and Singleton Births, 1975-1998

\begin{tabular}{|c|c|c|c|c|c|c|c|c|c|c|c|c|c|c|}
\hline \multirow[b]{2}{*}{ Year } & \multirow[b]{2}{*}{$3 \mathrm{LB}$} & \multicolumn{3}{|c|}{ Like-sex Triplet Deliveries } & \multicolumn{6}{|c|}{ Unlike-sex Triplet Deliveries } & \multicolumn{3}{|c|}{ Overall Triplets ${ }^{\mathrm{a}}$} & \multirow{2}{*}{$\begin{array}{c}\text { Singletons } \\
\text { SR }\end{array}$} \\
\hline & & $\begin{array}{l}2 \mathrm{LB}, \\
1 S B\end{array}$ & $\begin{array}{l}\text { 1LB, } \\
2 S B\end{array}$ & $3 S B$ & Total & SR & $3 \mathrm{LB}$ & $\begin{array}{l}\text { 2LB, } \\
1 S B\end{array}$ & $\begin{array}{l}\text { 1LB, } \\
2 \mathrm{SB}\end{array}$ & $3 S B$ & Total & SR & SR & \\
\hline 1975 & 46 & 9 & 2 & 23 & 80 & 342 & 29 & 5 & 2 & 5 & 41 & $195^{* *}$ & 308 & 50 \\
\hline 1976 & 50 & 7 & 2 & 20 & 79 & 300 & 24 & 4 & 0 & 6 & 34 & 216 & 299 & 52 \\
\hline 1977 & 53 & 4 & 4 & 20 & 81 & 296 & 31 & 5 & 0 & 5 & 41 & $163^{* *}$ & 281 & 51 \\
\hline 1978 & 59 & 5 & 2 & 12 & 78 & 192 & 37 & 1 & 0 & 4 & 42 & $103^{*}$ & 179 & 48 \\
\hline 1979 & 47 & 4 & 2 & 18 & 71 & 291 & 36 & 5 & 1 & 7 & 49 & $190^{*}$ & 264 & 47 \\
\hline 1980 & 52 & 7 & 1 & 15 & 75 & 240 & 36 & 1 & 2 & 5 & 44 & 152 & 235 & 46 \\
\hline 1981 & 62 & 7 & 4 & 19 & 92 & 261 & 45 & 3 & 1 & 3 & 52 & $90^{* *}$ & 220 & 48 \\
\hline 1982 & 53 & 5 & 4 & 20 & 82 & 297 & 54 & 8 & 1 & 10 & 73 & $183^{* *}$ & 268 & 48 \\
\hline 1983 & 60 & 5 & 4 & 12 & 81 & 202 & 36 & 3 & 0 & 7 & 46 & 174 & 251 & 45 \\
\hline 1984 & 58 & 6 & 1 & 16 & 81 & 230 & 40 & 4 & 0 & 6 & 50 & 147 & 221 & 45 \\
\hline 1985 & 53 & 6 & 1 & 15 & 75 & 236 & 40 & 2 & 0 & 4 & 46 & $101^{* *}$ & 221 & 45 \\
\hline 1986 & 52 & 2 & 1 & 14 & 69 & 222 & 43 & 4 & 1 & 6 & 54 & 148 & 216 & 45 \\
\hline 1987 & 52 & 11 & 2 & 18 & 83 & 277 & 55 & 4 & 0 & 4 & 63 & $85^{* *}$ & 221 & 44 \\
\hline 1988 & 62 & 4 & 1 & 7 & 74 & 122 & 59 & 3 & 0 & 5 & 67 & 90 & 144 & 43 \\
\hline 1989 & 50 & 4 & 1 & 8 & 63 & 159 & 73 & 2 & 2 & 9 & 86 & 128 & 186 & 42 \\
\hline 1990 & 65 & 6 & 2 & 14 & 87 & 199 & 101 & 4 & 0 & 7 & 112 & $74^{* *}$ & 162 & 41 \\
\hline 1991 & 64 & 5 & 1 & 10 & 80 & 154 & 123 & 5 & 2 & 4 & 134 & $52^{* *}$ & 126 & 39 \\
\hline 1992 & 98 & 2 & 1 & 7 & 108 & 77 & 138 & 10 & 1 & 8 & 157 & 76 & 141 & 38 \\
\hline 1993 & 79 & 3 & 1 & 10 & 93 & 125 & 152 & 13 & 3 & 9 & 177 & 87 & 132 & 36 \\
\hline 1994 & 103 & 4 & 0 & 8 & 115 & 81 & 194 & 6 & 3 & 11 & 214 & 70 & 111 & 33 \\
\hline 1995 & 94 & 6 & 0 & 7 & 107 & 84 & 183 & 8 & 2 & 11 & 204 & 74 & 122 & 31 \\
\hline 1996 & 107 & 5 & 0 & 8 & 120 & 81 & 179 & 4 & 0 & 5 & 188 & $34^{* *}$ & 75 & 31 \\
\hline 1997 & 86 & 4 & 4 & 13 & 107 & 159 & 181 & 10 & 0 & 5 & 196 & $43^{* *}$ & 112 & 31 \\
\hline 1998 & 109 & 2 & 0 & 5 & 116 & 49 & 195 & 6 & 2 & 8 & 211 & 54 & 75 & 31 \\
\hline
\end{tabular}

Note: LB: Live births; SB: Stillbirths; SR: Stillbirth rate per 1000 births, ${ }^{*}$ Comparison of like-sexed and unlike-sexed triplets, $p<0.05,{ }^{* *} p<0.01$; a: Individual triplet births including unknown sexes. 
Table 2

Stillbirth Rates of Like- and Unlike-sex Triplets According to Maternal Age, 1975-1998

\begin{tabular}{|c|c|c|c|c|c|c|c|c|c|}
\hline \multirow{3}{*}{ Period } & & \multicolumn{8}{|c|}{ Maternal age } \\
\hline & & \multicolumn{2}{|c|}{ Less than 25} & \multicolumn{2}{|c|}{$25-29$} & \multicolumn{2}{|c|}{$30-34$} & \multicolumn{2}{|c|}{35 or more } \\
\hline & & $\begin{array}{l}\text { Like- } \\
\text { sexed }\end{array}$ & $\begin{array}{l}\text { Unlike- } \\
\text { sexed }\end{array}$ & $\begin{array}{l}\text { Like- } \\
\text { sexed }\end{array}$ & $\begin{array}{l}\text { Unlike- } \\
\text { sexed }\end{array}$ & $\begin{array}{l}\text { Like- } \\
\text { sexed }\end{array}$ & $\begin{array}{l}\text { Unlike- } \\
\text { sexed }\end{array}$ & $\begin{array}{l}\text { Like- } \\
\text { sexed }\end{array}$ & $\begin{array}{r}\text { Unlike- } \\
\text { sexed }\end{array}$ \\
\hline \multirow[t]{2}{*}{ 1975-1978 } & No. of triplet sets & 59 & 27 & 175 & 90 & 71 & 36 & 15 & 5 \\
\hline & Stillbirth rate & 232 & 160 & 278 & 178 & 300 & 139 & 487 & 200 \\
\hline \multirow[t]{2}{*}{ 1979-1982 } & No. of triplet sets & 60 & 24 & 156 & 114 & 81 & 72 & 23 & 8 \\
\hline & Stillbirth rate & 333 & 139 & 235 & 155 & 272 & 125 & 362 & 500 \\
\hline \multirow[t]{2}{*}{ 1983-1986 } & No. of triplet sets & 45 & 18 & 144 & 99 & 97 & 63 & 20 & 16 \\
\hline & Stillbirth rate & 385 & 19 & 178 & 118 & 216 & 185 & 200 & 271 \\
\hline \multirow[t]{2}{*}{ 1987-1990 } & No. of triplet sets & 42 & 31 & 150 & 150 & 87 & 123 & 28 & 24 \\
\hline & Stillbirth rate & 246 & 129 & 213 & 69 & 126 & 114 & 214 & 97 \\
\hline \multirow[t]{2}{*}{ 1991-1994 } & No. of triplet sets & 35 & 44 & 186 & 250 & 145 & 308 & 30 & 81 \\
\hline & Stillbirth rate & 257 & 205 & 86 & 71 & 99 & 63 & 78 & 41 \\
\hline \multirow[t]{2}{*}{ 1995-1998 } & No. of triplet sets & 34 & 34 & 161 & 264 & 172 & 376 & 83 & 125 \\
\hline & Stillbirth rate & 186 & 69 & 101 & 62 & 45 & 49 & 133 & 32 \\
\hline \multirow{2}{*}{\multicolumn{2}{|c|}{$\begin{array}{l}\text { Regression coefficient } \\
\text { (Standard error) }\end{array}$}} & -0.0042 & -0.0011 & $-0.0093^{*}$ & $-0.0063^{* *}$ & $-0.0135^{* *}$ & -0.0051 & $-0.0187^{*}$ & -0.0171 \\
\hline & & $(0.0044)$ & $(0.0044)$ & $(0.0021)$ & $(0.0010)$ & $(0.0010)$ & $(0.0022)$ & $(0.0041)$ & $(0.0083)$ \\
\hline
\end{tabular}

Note: * Significant at the $5 \%$ level, ${ }^{* *}$ Significant at the $1 \%$ level.

\section{Effect of Gestational Age}

Table 3 shows 4 -yearly changes in stillbirth rates of triplets according to the sex composition of each triplet set and gestational age during that 4-year period. With one exception, the stillbirth rate was higher in like- than in unlike-sex triplets in each gestational age group. Differences in stillbirth rates between like- and unlike-sex triplets were statistically significant in six combinations of year-periods and gestational ages (Table 3). The stillbirth rate decreased from 1979-1982 to 1995-1998 for both like- and unlike-sex triplets, except for in the 23 weeks or less gestation group. In this group the stillbirth rate slowly, though not significantly, decreased from 964 to 870 for like-sex, and from 867 to 824 for unlike-sex triplets. For the gestational groups of 24 weeks or more, the stillbirth rate significantly decreased along the years for both like- and unlikesex triplets.

Table 4 shows the relationship between stillbirth rates of triplets and gestational ages in the period 1979-1998. The rate was the lowest at 34 weeks (17), followed by 35 weeks (18). When the year of birth was divided into two periods, 1979-1988 and

Table 3

Trends in Stillbirth Rates for Like- and Unlike-sex Triplets According to Gestational Ages, 1979-1998

\begin{tabular}{|c|c|c|c|c|c|}
\hline \multirow[t]{2}{*}{ Year } & \multicolumn{4}{|c|}{ Gestational Age (weeks) } & \multirow[b]{2}{*}{$36+$} \\
\hline & -23 & $24-27$ & $28-31$ & $32-35$ & \\
\hline \multicolumn{6}{|c|}{ Like-sex Triplets } \\
\hline 1979-1982 & $964^{*}(56)$ & $706(17)$ & $190 *(49)$ & $56(89)$ & $61(109)$ \\
\hline 1983-1986 & $981(53)$ & $438 *(16)$ & $75(40)$ & $39(86)$ & $24(111)$ \\
\hline 1987-1990 & $976^{*}(42)$ & $354^{*}(16)$ & $98(41)$ & $37(108)$ & $47^{*}(100)$ \\
\hline 1991-1994 & $854(41)$ & $111(18)$ & $33(71)$ & $11(179)$ & $4(87)$ \\
\hline 1995-1998 & $870(36)$ & $138(29)$ & $26(91)$ & $10(238)$ & $24(56)$ \\
\hline \multicolumn{6}{|c|}{ Unlike-sex Triplets } \\
\hline 1979-1982 & $867(20)$ & $561(19)$ & $63(16)$ & $24(69)$ & $35(94)$ \\
\hline 1983-1986 & $944(24)$ & $125(8)$ & $67(25)$ & $32(62)$ & $9(77)$ \\
\hline 1987-1990 & $800(30)$ & $51(13)$ & $47(50)$ & $19(124)$ & $12(111)$ \\
\hline 1991-1994 & $778(45)$ & $59(45)$ & $18(114)$ & $17(320)$ & $27(158)$ \\
\hline 1995-1998 & $824(34)$ & $87(50)$ & $25(144)$ & $8(445)$ & $11(126)$ \\
\hline
\end{tabular}

Note: (): The figures in parentheses indicate the number of triplet sets.

* Comparison of SRs in triplets for two types, $p<.05$. 
Table 4

Stillbirth Rates of Each Triplet Birth According to Gestational Ages, 1979-1998

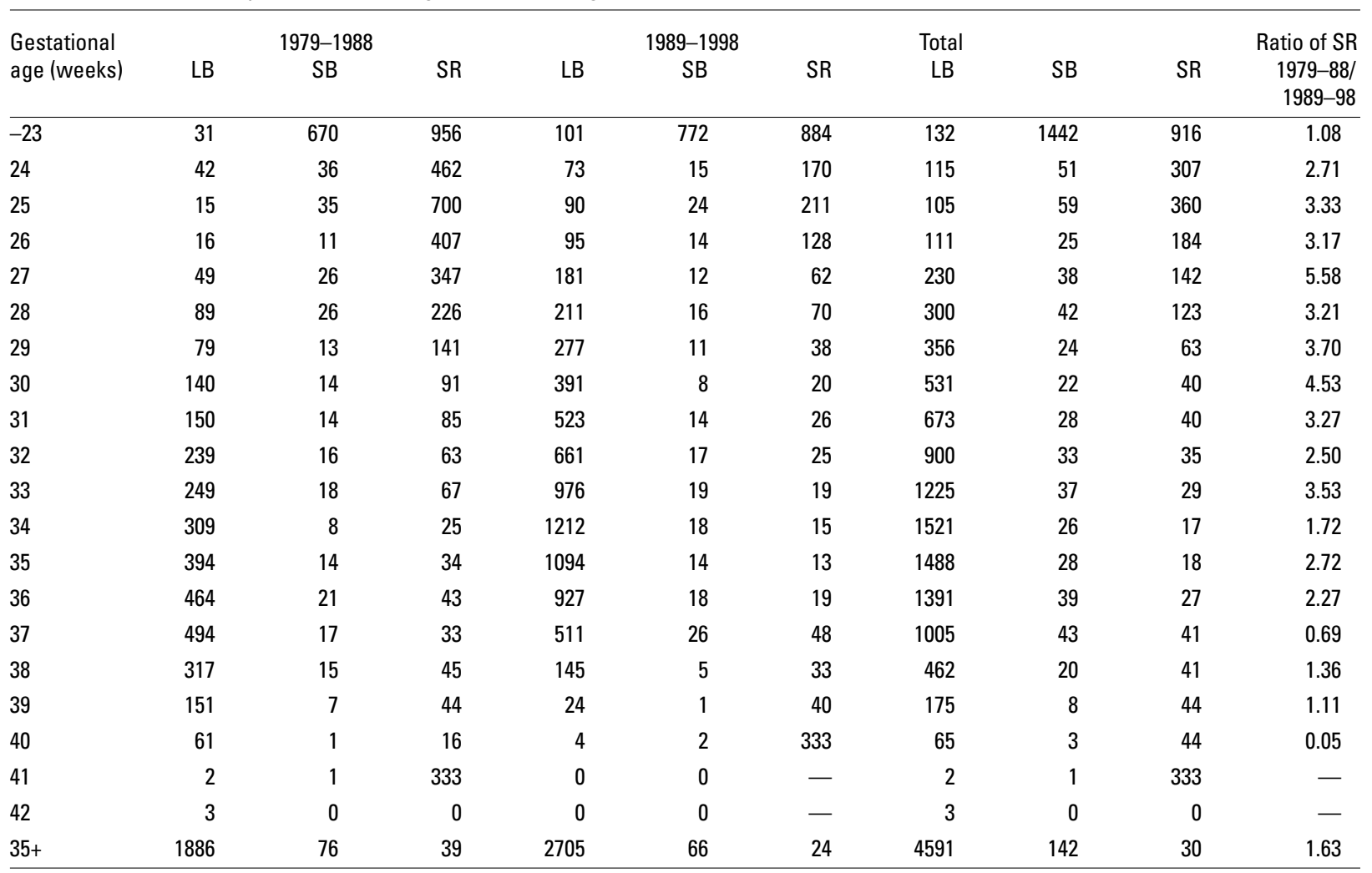

Note: LB: Live births; SB: Stillbirths; SR: Stillbirth rate per 1000 births.

1989-1998, the stillbirth rate was the lowest at 34 or 35 weeks for both periods. Although the stillbirth rate decreased at every gestational age in the latter period (1989-98), it decreased to less than a third at shorter gestational ages: $25-31$ and 33 weeks.

\section{Effect of Birthweight on Stillbirth Rates}

Table 5 shows stillbirth rates of like- and unlike-sex triplets according to birthweight for a triplet set during the period from 1979 to 1998. Stillbirth rates of both types of triplets decreased with birthweight of triplets. The lowest stillbirth rate was observed at birthweight 6001-6500g in like-sex triplets (9 per 1000 births) and 7000g or more in unlike-sex triplets (7). With one exception, the stillbirth rate was higher in like- than in unlike-sex triplets. However, stillbirth rates were significantly higher only at $3000 \mathrm{~g}$ or less and 4501-5000g.

\section{Effect of Gestational Age and Birthweight on Stillbirth Rates}

Table 6 shows stillbirth rates of triplets according to gestational age and birthweight for a triplet set during the period from 1979 to 1998 . When the categories with less than eight sets were neglected, the stillbirth rate of triplets was the lowest (21) at 24-27 weeks of gestation and birthweight $3500 \mathrm{~g}$ or less. At 3501-5000g, the stillbirth rate was always the lowest at 28-31 weeks; at birthweight $5001 \mathrm{~g}$ or more, the stillbirth rate was lower at 32-35 weeks than at 36 weeks or more. The lowest stillbirth rate of triplets was 0 at $4501-5000 \mathrm{~g}$ and $28-31$ weeks and at $7001 \mathrm{~g}$ or more and 32-35 weeks. The second and third lowest rates were five at 6001-6500g and 32-35

\section{Table 5}

Stillbirth Rate of Like-sexed and Unlike-sexed Triplets According to Birthweight of Triplet Sets, 1979-1998

\begin{tabular}{lrrrc}
\hline \multirow{2}{*}{$\begin{array}{l}\text { Weight at } \\
\text { Birth }(\mathrm{g})\end{array}$} & \multicolumn{2}{c}{ Like-sex Triplets } & \multicolumn{2}{c}{ Unlike-sex Triplets } \\
\hline-2000 & Sets $(n)$ & SR & Sets $(n)$ & SR \\
\hline $2001-2500$ & 47 & 869 & 193 & $715^{*}$ \\
$2501-3000$ & 64 & 162 & 51 & $150^{*}$ \\
$3001-3500$ & 69 & 53 & 92 & $53^{*}$ \\
$3501-4000$ & 106 & 72 & 139 & 72 \\
$4001-4500$ & 167 & 36 & 180 & 41 \\
$4501-5000$ & 159 & 29 & 253 & 22 \\
$5001-5500$ & 216 & 25 & 312 & $12^{*}$ \\
$5501-6000$ & 230 & 17 & 309 & 15 \\
$6001-6500$ & 190 & 9 & 277 & 8 \\
$6501-7000$ & 135 & 12 & 195 & 9 \\
$7001-$ & 128 & 13 & 137 & 7 \\
\hline
\end{tabular}

Note: SR: Stillbirth rate per 1000 births.

* Comparison of SRs in triplets for two types, $p<.05$. 


\begin{tabular}{|c|c|c|c|c|c|}
\hline \multicolumn{6}{|c|}{$\begin{array}{l}\text { Stillbirth Rate of Triplets According to Gestational Age } \\
\text { and Birthweight of Triplets Sets, 1979-1998 }\end{array}$} \\
\hline \multirow{2}{*}{$\begin{array}{l}\text { Weight at } \\
\text { Birth }(g)\end{array}$} & \multicolumn{5}{|c|}{ Gestational age (weeks) } \\
\hline & -23 & $24-27$ & $28-31$ & $32-35$ & $36+$ \\
\hline-2000 & 915 (491) & $368(78)$ & $690(14)$ & $1000(1)$ & - \\
\hline $2001-2500$ & $800(5)$ & $225(74)$ & $300(20)$ & $333(1)$ & 一 \\
\hline $2501-3000$ & $1000(1)$ & $92(65)$ & $78(77)$ & $533(5)$ & $467(5)$ \\
\hline $3001-3500$ & - & $21(16)$ & $50(126)$ & $197(22)$ & $556(6)$ \\
\hline $3501-4000$ & $333(1)$ & $222(3)$ & 30 (178) & $126(66)$ & $278(6)$ \\
\hline $4001-4500$ & - & - & $13(157)$ & $30(179)$ & $271(16)$ \\
\hline $4501-5000$ & - & - & $0(64)$ & $15(329)$ & $187(25)$ \\
\hline $5001-5500$ & - & - & $0(7)$ & $13(448)$ & $69(77)$ \\
\hline $5501-6000$ & - & - & $0(2)$ & $8(369)$ & $24(168$ \\
\hline $6001-6500$ & - & - & $0(2)$ & $5(221)$ & $14(245$ \\
\hline $6501-7000$ & - & - & - & $9(76)$ & $10(254$ \\
\hline $7001-$ & - & - & - & $0(19)$ & $11(246$ \\
\hline
\end{tabular}

Note: (): The figures in parentheses indicate the number of triplet sets.

weeks and eight at 5501-6000g and 32-35 weeks, respectively.

\section{Discussion}

Stillbirth rates of triplets in Japan were 49 for like-sex and 54 for unlike-sex triplets in 1998. The corresponding figures in 1955 were 498 and 453, respectively (Imaizumi \& Inouye, 1980). The stillbirth rate in 1998 decreased to one-tenth for like-sex and to one-eighth for unlike-sex triplets during the 43year period from 1955 .

The stillbirth rates for singleton pregnancies in Japan from vital statistics were 94 in 1955 and 31 in 1998, where the rate decreased to one-third during the 43-year period. The stillbirth rate for twins was 257 in 1955 (Imaizumi et al.,1980) and 66 (1493/22555) in 1998 (from vital statistics in Japan), where the rate decreased to be one quarter of what it was at the beginning of the 43-year period. Therefore, the most drastic decline in the stillbirth rate was seen in like-sex triplets, followed by unlike-sex triplets, twins and singletons.

As shown in Table 1, stillbirth rates were generally greater in like- than in unlike-sex triplets. Although the rate decreased during the 23 years for both sex compositions, the overall stillbirth rate may have been confounded by the proportion of like-sex triplet sets. The ratio of like- to unlike-sex triplet sets was about 2:1 in 1975 and about 1:2 in 1998. The decline in the rate for the overall triplet sets was considered to be due to the increased proportion of unlike-sex sets, which generally had a lower stillbirth rate. If we assume that the ratio of the like- to the unlike-sex sets had been that for the year 1975 (namely, 80 and 41), then the values for the overall stillbirth rate for the rest of the years would be expected to be higher than the observed.
The distinct increase in the proportion of unlikesex triplets is probably explained by the concurrent increase in trizygotic triplets. According to Imaizumi (2003), trizygotic triplet rates increased rapidly after 1987 in Japan. This implies that like-sex triplets included more trizygotic triplets after 1987. If we assume a random distribution of sex among trizygotic triplets, two out of eight sets would be like-sex (the ratio of the unlike- and the like-sex was 3:1). As in 1998, if the number of like-sex sets was half that of the unlike-sex sets, two thirds of the like-sex triplets would be trizygotic. This may be one of the reasons for stillbirth rates in like-sex triplets decreasing more rapidly than in unlike-sex triplets during the period from 1975 to 1998 (see Table 1).

The proportion of shorter gestational age, 12-23 weeks of gestation, decreased from $17.5 \%(56 / 320)$ in $1979-1982$ to $8.0 \%(36 / 450)$ in $1995-1998$ for likesex triplets; the corresponding figures were $9.2 \%$ $(20 / 218)$ and $6.5 \%$ (50/765) for unlike-sex triplets, respectively, (Table 3). As for birthweights of a triplet set, the proportion under $2000 \mathrm{~g}$ decreased from $19.6 \%(154 / 786)$ in $1979-1988$ to $11.2 \%(112 / 1001)$ in 1989-1998 for like-sex triplets; the corresponding figures were $11.5 \%(63 / 546)$ and $7.7 \%(131 / 1695)$ for unlike-sex triplets, respectively. Because shorter gestational age and lower birthweight are risk factors for stillbirths, these trends would have contributed to the decrease in the stillbirth rates during the period studied. However, the declining stillbirth rate of triplets may be attributed more directly to improvements in antenatal and perinatal medical care, which may have been more effective even for triplet deliveries at shorter gestational ages (Table 4).

According to Luke (1996), the lowest stillbirth rate of triplets was $0.33 \%$ at $2500-2800 \mathrm{~g}$ and $36-37$ weeks during the period from 1983 to 1988 in the United States. However, in the present study, the lowest stillbirth rate of triplets was 0 at $4501-5000 \mathrm{~g}$ for a triplet set and 28-31 weeks, followed by 6001-6500g $(0.45 \%), 5501-6000 \mathrm{~g}(0.81 \%)$, and $6501-7000 \mathrm{~g}(0.88 \%)$ at $32-35$ weeks during the period from 1979 to 1998 . It should be noted that the birthweight was calculated as a set in the present study, while the data in the United States was shown on an individual basis (Luke, 1996). Moreover, American women are generally taller than Japanese women, and birthweight is also higher on average in American than Japanese babies. Therefore, it is difficult to compare the present results directly with Luke's (Luke, 1996). However, lower stillbirth rates are seen in similar conditions in both studies. Considering a comparison of gestational age with relatively lower stillbirth rates (Table 4), it is recommended that the optimum time for Japanese women carrying triplets to give birth is at $32-35$ weeks of gestation.

From this study, it is suggested that risk factors for stillbirth among triplets were the like-sex composition 
(Table 1), maternal age groups less than 20 years and 35 years or more (Table 2), shorter gestational age (Table 3) and lower birthweight (Table 5).

\section{Acknowledgment}

We are grateful to the staff of Health and Welfare Statistics and Information Department, Ministry of Health and Welfare, Japan.

\section{References}

Barr, A., \& Stevenson, A. C. (1961). Stillbirths and infant mortality in twins. Annals of Human Genetics, 25, 131-140.

Derom, R., Orelebeke, J., Eriksson, A., \& Thiery, M. (1995). The epidemiology of multiple births in Europe. In L. G. Keith, E. Papiernik, D. Keith, \& B. Luke (Eds.), Multiple pregnancy: Epidemiology, gestation and perinatal outcome (pp. 145-162). New York: The Parthenon Publishing Group.

Imaizumi, Y. (1998). A comparative study of twinning and triplet rates in 17 countries, 1972-1996. Acta Geneticae Medicae et Gemellologiae, 47, 101-114.

Imaizumi, Y. (2003). A comparative study of zygotic twinning and triplet rates in eight countries, 1972-1999. Journal of Biosocial Science, 35, 287-302.
Imaizumi, Y., Asaka, A., \& Inouye, E. (1980). Analysis of multiple birth rates in Japan. II. Secular trend and effect of birth order, maternal age and gestational age in stillbirth rates of twins. Acta Geneticae Medicae et Gemellologiae, 29, 223-231.

Imaizumi, Y., \& Inouye, E. (1980). Analysis of multiple birth rates in Japan. IV. Secular trend, effect of maternal age and gestational age in stillbirth rates of triplets. The Japanese Journal of Human Genetics, $25,219-227$.

Imaizumi, Y., \& Nonaka, K. (1998). Yearly changes in stillbirth rates of zygotic twins in Japan, 1975-1994. Acta Geneticae Medicae et Gemellologiae, 47, 19-30.

Jonas, H. A., \& Lumley, J. (1993). Triplets and quadruplets born in Victoria between 1982 and 1990. The impact of IVF and GIFT on rising birth rates. Medical Journal of Australia, 158, 659-663.

Luke, B. (1996). Reducing fetal deaths in multiple births: optimal birthweights and gestational ages for infants of twin and triplets births. Acta Geneticae et Gemellologiae, 45, 333-348.

West, C. R., Adi, Y., \& Pharoah, P. O. (1999). Fetal and infant death in mono- and dizygotic twins in England and Wales 1982-91. Archives of Disease in Childhood. Fetal and Neonatal Ed, 80, F217-220. 